\begin{tabular}{|c|l|}
\hline Title & Characteristic precipitation patterns of El Niño/La Niña in time variable gravity fields by GRA CE \\
\hline Author(s) & Morishita, Y u; Heki, Kosuke \\
\hline Citation & $\begin{array}{l}\text { Earth and Planetary Science Letters, 272(3-4), 677-682 } \\
\text { https://doi.org/L0.1016/.epsl.2008.06.003 }\end{array}$ \\
\hline Issue Date & 2008_08_15 \\
\hline Doc URL & http://hdl.handle.net/2115/34505 \\
\hline Type & article(author version) \\
\hline File Information & Morishita_EPSL_final.pdf \\
\hline
\end{tabular}

Instructions for use 
Earth Planet. Sci. Lett., 272, 677-682, 2008.

\title{
Characteristic precipitation patterns of El Niño / La Niña in time-variable gravity fields by GRACE
}

\author{
Yu Morishita ${ }^{1}$ \& Kosuke Heki \\ Dept. Natural History Sci., Hokkaido University, Sapporo 060-0810, Japan. \\ Tel/Fax: +81-11-706-3826, email: heki@mail.sci.hokudai.ac.jp \\ ${ }^{1}$ Now at Geographical Survey Institute, Tsukuba, Japan
}

\begin{abstract}
El Niño and La Niña are known to bring about characteristic patterns of anomalous precipitation in various regions of the world. We extracted temporary and regional gravity changes from monthly gravity fields recovered by the GRACE satellites, and converted them to the changes in surface mass, possibly ground or subsurface water in land area. Such mass changes in the 2006-2007 El Niño and 2005-2006 La Niña episodes agreed well with precipitation anomaly patterns inferred from meteorological records in tens of past such episodes. We further compared them with anomalies of soil moisture numerically simulated by integrating monthly precipitation and evapotranspiration. They agree quantitatively with the GRACE data, suggesting that temporal changes in terrestrial water storage in low-latitude region are largely governed by precipitation. This study demonstrates the potential of satellite gravimetry as a sensor of inter-annual climate changes.
\end{abstract}

Keywords: El Niño, La Niña, GRACE, terrestrial water storage, soil moisture

\section{Introduction}

GRACE (Gravity Recovery and Climate Experiment) is a set of twin satellites separated by 220 $\mathrm{km}$ in a polar orbit at an altitude of $\sim 500 \mathrm{~km}$. Precise inter-satellite ranging allows us to draw global gravity anomaly maps with a time resolution of a month. Such time-variable gravity fields provide information on redistribution of various forms of surface water, e.g. ocean, soil moisture, snowpack, mountain glaciers, and continental ice sheets [1]. Shortly after its launch in March 2002, GRACE started to produce important scientific results on the dynamics of water [2, 3]. A few diverse examples include detections of the global warming signatures in decreasing ice mass in southern Alaska [4], and in southern Greenland [5], where acceleration of ice mass loss is suggested to have occurred in spring 2004 [6]. In the ocean, they observed seasonal changes of the global ocean mass [7], as well as regional semi-closed ocean basin [8]. Possible postseismic movement of supercritical water deep in mantle was detected after the 2004 Sumatra Earthquake [9].

The largest contribution of GRACE would be to hydrological studies of terrestrial water storages. Seasonal changes in water storages were investigated in major river basins in the world [10-12]. By comparing such GRACE observations with those simulated in Global Land Data Assimilation System (GLDAS), they are clarifying quantitative relationships between seasonal changes in fluxes 
(e.g. evapotranspiration, runoff, and precipitation) and storages (e.g. soil moisture, snowpack) of ground water in various parts of the world [13]. Such hydrological cycles also plays a major role in the Earth's climate system [14]. In addition to academic significance, GRACE observations, with an integrated measure of available water on land, provide key information for the management of freshwater resources [15].

El Niño was originally thought to be a regional phenomenon that sea surface temperature (SST) temporarily rises in the equatorial eastern Pacific Ocean (off the Peru coast) for one half year or more, but is now deemed a global episode entangling the Earth system and referred to as ENSO (El Niño and Southern Oscillation). It changes not only precipitation patterns in the equatorial Pacific area, but also imposes climate changes in remote areas by teleconnection. Ropelewski and Halpert [16] compiled regional precipitation anomaly patterns accompanying ENSO in meteorological records in 25 past episodes since $19^{\text {th }}$ century; they occur in Indian subcontinent, eastern and southern Africa, South America, and southern North America (Fig. 1). They also showed that such precipitation anomalies reverse their polarities for La Niña [17], the episode opposite to El Niño characterized by low SST off Peru. Later they quantified the shifts in the median precipitation amounts in these episodes [18]. A recent study with a new precipitation data set over a longer time span and with a different statistical approach basically supports the original picture [19].

Precipitation anomalies leave signatures in gravity fields in land area through changes in soil moisture. Here we try to detect gravity signals related to such episodes in time-variable gravity data from GRACE 2002-2007, which includes two El Niño and one La Niña episodes (Fig. 2).

\section{Methods and results}

\section{2-1. Gravity deviation and equivalent water thickness}

We used the Level 2 GRACE data (Release 04) by CSR (Center for Space Res., Univ. Texas) (http://podaac.jpl.nasa.gov/grace/index.html), consisting of 62 monthly sets of spherical harmonic (Stokes) coefficients complete to degree and order 60, from April 2002 to August 2007. In order to suppress larger errors in the higher degree coefficients, we applied spatial averaging with a Gaussian averaging function (averaging radius of $500 \mathrm{~km}$ ) [1]. Usually, the $C_{20}$ coefficients are not used because of their large uncertainties in the GRACE products. We discuss anomalies in a relatively small scale, and we confirmed that the replacement of this coefficient with those derived by Satellite Laser Ranging [20] hardly changed our results. In the present study, we do not include the changes in $C_{20}$. In order to compare gravity with meteorological quantities, we often calculate the depths of equivalent surface water responsible for the temporary gravity deviations (we do not call it "gravity anomaly," which generally means spatial difference of static gravity). Gravity deviations include not only the gravitational pull of the surface loads themselves but also the secondary component coming from the deformed solid Earth. We can remove this secondary component and convert Stokes' coefficients $C_{\mathrm{nm}}$ and $S_{\mathrm{nm}}$ into surface water thicknesses $\sigma$ at latitude $\theta$ and longitude $\phi$, i.e.

$$
\Delta \sigma(\theta, \phi)=\frac{R \rho_{\text {ave }}}{3} \sum_{n=2}^{\infty} \sum_{m=0}^{n} \frac{2 n+1}{1+k_{n}}\left(\Delta C_{n m} \cos m \phi+\Delta S_{n m} \sin m \phi\right) P_{n m}(\sin \theta),
$$

where $k_{\mathrm{n}}, R$, and $\rho_{\text {ave }}$ denotes the $n$ 'th degree load Love number, the radius, and the average density of the Earth, respectively [1]. $P_{\mathrm{nm}}(\sin \theta)$ is the $n$ 'th degree and $m$ 'th order fully-normalized Legendre function, and $\Delta$ indicates the deviation from the reference value.

Fig. 3 shows time series of water thickness on the Earth's surface derived from monthly GRACE 
data sets at a point in Tanzania, Africa, and a point in Brazil, South America, and model curves composed of constant, linear, quadratic, and seasonal (annual and semiannual) terms (linear and quadratic components are removed in the figure). The changes match fairly well for most of the period with these curves, but deviate occasionally from them. For example, the gravity in Tanzania shows relatively large negative (positive) deviations in early 2006 (2007), which correspond to the recent La Niña (El Niño) episodes (Fig. 2). Those in Brazil show positive deviations in early 2006. Such deviations exceed $3 \sigma$ at their maxima and might represent the precipitation anomalies associated with these episodes.

There is no single definition of El Niño and La Niña universally agreed upon. The Japan Meteorological Agency (JMA) uses the SST in a rectangle (NINO.3), 5S-5N, and 150W-90W; they define El Niño (La Niña) as the period when the 5 months moving average of the SST in NINO.3 are higher (lower) than the reference temperature (monthly mean for the past 30 years) by $>0.5$ degrees for $\geq 6$ months. The two $\sim 0.5$ year periods, 2005-2006, and 2006-2007, are similar in length, although the latter is a bit too short to be an El Niño episode in the JMA definition (Fig. 2). The other high SST period 2002-2003 is not discussed here because the gravity data are noisier in the first year of GRACE observations due to technical problems (also precipitation anomalies are not clear in these continents for this episode, see Fig. 6). We here treat the 2006-2007 episode as representing El Niño.

We selected the two epochs, i.e. Feb. 2006 and Feb. 2007, representing La Niña and El Niño, respectively, because precipitation anomalies tend to occur in Africa and South America in February in an idealized episode [16-18]. Actually, the El Niño episode ends at some time during 2007 February (Fig.2), but relatively large gravity signatures are expected at the ends of anomalous precipitation periods because they reflect temporally integrated precipitation anomalies. Nevertheless, relatively short duration of this El Niño episode may have made the results less clear than those in the La Niña episode one year before. Precipitation anomaly in Indian subcontinent is expected in July, but we will not discuss this region here because the two relatively short episodes discussed here do not include July.

Fig.4 shows geographical extent of the anomalies of surface water thickness at the two epochs, Feb. 2006 and Feb. 2007. We repeated the same regression analyses for individual Stokes' coefficients as in Fig. 3, and used their deviations from model seasonal curves (not deviations from the averages) at the two epochs as $\Delta C_{\mathrm{nm}}$ and $\Delta S_{\mathrm{nm}}$ in equation (1) to derive water thickness anomalies. There we see north-south stripes due to correlated errors [21], but quite systematic surface mass anomalies are also recognized in Africa and South America. Their distribution is similar to those in past episodes (Fig. 1), and the deviations in the 2006 and 2007 epochs are opposite in sense to each other. Fig.5 demonstrates that the deviation values at grid points in Africa and South America are negatively correlated between the two epochs. There we limited the points to be correlated to the region with latitude between $30 \mathrm{~S}$ and $5 \mathrm{~N}$, longitude between $10 \mathrm{E}$ and $55 \mathrm{E}$, in Africa, and latitude between $35 \mathrm{~S}$ and 10N, longitude between 285E and 325E, in South America. Slightly smaller values in Feb. 2007 than in Feb. 2006 in South America (Fig.5b) may reflect the short duration of the 2006-2007 episode.

\section{2-2. Soil moistures}

We simulated changes of soil moisture $W(t)$ at an arbitrary point using monthly precipitation $P(t)$ and evapotranspiration $E(t)$ in order to validate changes seen in Fig. 4. In a simple bucket model, when precipitation (input) exceeds evapotranspiration ( $1^{\text {st }}$ output), soil becomes moister by the 
amount of their difference. Input exceeding the soil capacity is lost as runoff ( $2^{\text {nd }}$ output) $R(t)$, i.e.

$$
d W(t) / d t=P(t)-R(t)-E(t)
$$

No further evapotranspiration occurs when the soil dries up. River runoff and soil capacities are difficult to measure. On the other hand, $P(t)$ is available worldwide on line from CMAP (ftp.cdc.noaa.gov/Datasets/cmap/std/precip.mon.mean.nc, Climate Prediction Center Merged Analysis of Precipitation) at $2.5 \times 2.5$ degree grids (standard), and we can infer $E(t)$ from temperature, hours of sunlight, and precipitation using appropriate models [22].

In this study, in order to compare with GRACE results, we extracted the seasonally changing component of $W(t)$ by the three steps, (1) calculate differences between $P(t)$ from CMAP data and model-derived $E(t)$ at grid points, (2) estimate best-fit constant and linear terms in the $P(t)-E(t)$ time series, and (3) integrate the residuals to recover seasonal components. Crowley et al. [11] reported good agreements between land water storage anomalies from the GRACE data and integrated monthly precipitation anomalies within the Congo Basin, Africa. Our procedure is similar to those employed in Crowley et al. [11] with one difference that we obtained best-fit constant and linear terms for $P(t)-E(t)$ while they did it for $P(t)$. We calculated $E(t)$ after the equation 7-66 in Dingman [22] and NCEP (National Centers for Environment Prediction) temperature data. The potential evapotranspiration was calculated after Hamon's [23] model.

The obtained time series still include seasonal changes of $R(t)$ as well as those of $W(t)$. Because the two quantities would change more or less in phase (i.e. more runoff from wetter soil), the obtained time-series is an exaggerated version of the seasonal changes in soil moisture. Fig. 6 shows the time series of soil moisture at points in Tanzania and Brazil simulated in this way using the CMAP monthly precipitation (shown at the bottom as vertical bars). The changes in Tanzania (Fig. 6a) behave similarly to those from GRACE in Fig. 3; it deviates from the standard seasonal curve during the El Niño and La Niña episodes. Similarity in Brazil is not so clear; soil moisture deviates occasionally from the standard seasonal curve even when neither El Niño nor La Niña episodes are occurring (e.g. late in 2004). Nevertheless, deviations around the two epochs discussed here have certain similarities to the GRACE results. Fig. 7 shows geographical extent of such soil moisture anomalies in Africa and South America at the two epochs. There the same $500 \mathrm{~km}$ Gaussian filter has been applied (soil moisture anomalies were set to zero in oceans before we applied the spatial filter) so that their resemblance to the GRACE results in Fig. 4 can be directly recognized. Fig.8 shows the positive correlations between values obtained by GRACE and CMAP at grid points within African and South American continents in the two epochs (we used the same spatial window as in Fig.5).

\section{2-3. Comparison}

Ropelewski and Halpert $[16,17]$ characterized ENSO-related precipitation pattern changes in various regions from available ground meteorological data since the $19^{\text {th }}$ century. The largest change occurs in the tropical Pacific, i.e. reduced/enhanced rainfall continues June-November/May-April in Indonesia/Central Pacific during a typical El Niño episode. Anomalous precipitations in oceans, however, do not make gravity signals measurable with GRACE. Here we focus on the precipitation anomalies on lands, where precipitation leaves temporary gravity signatures through soil moisture changes.

According to Ropelewski and Halpert [16], the precipitation tends to decrease in southern Africa, 
northern South America, central and eastern Australia, and increase in eastern tropical Africa, southeastern South America, southern North America, with the probabilities of 80-90 percents during El Niño episodes (Fig. 1). Such anomalies, unlike those in the Pacific, concentrate on a few months in an episode; those in Africa and South America are remarkable in the northern winter months. They suggested that the anomalies in Africa are due to the equator-ward shift of the lower atmospheric convergent zone which normally lies in more southerly latitudes. Small precipitation in northern South America is explained by the westward displacement of the Atlantic Walker circulation during ENSO episodes, and the enhanced precipitation in southern South America may be related to stronger subtropical westerlies associated with ENSO. Indeed, a see-saw oscillation of the precipitations between the Amazon and Congo basins seems to exist even when there are no SST anomalies off Peru [11, 24]. These patterns almost reverse themselves during La Niña episodes [17].

In Fig. 4, we can see positive gravity anomalies in southern Africa and northern South America, and negative anomalies in eastern equatorial Africa, southern North America, and eastern South America in February 2006 (La Niña). Almost opposite anomalies are seen in February 2007 (El Niño), i.e. the negative anomalies in northern South America, and positive ones in eastern equatorial Africa and eastern South America. Such patterns are consistent with Fig. 1, although anomalies expected in southern Africa and southern North America were not clear in the 2007 epoch due possibly to the shortness of this El Niño episode. With the good quantitative agreements between Figs. 4 and 7 (Fig.8), and their resemblance to Fig. 1, we may conclude that characteristic precipitation anomalies associated with La Niña/El Niño episodes leave water storage signatures large enough to be seen in the GRACE time-variable gravity fields.

\section{Discussion and conclusion}

Although characteristic precipitation anomaly patterns seen in past ENSO episodes (Fig. 1) agree with those recovered by GRACE (Fig. 4) to a large extent, there are some differences between them. For example, GRACE and CMAP showed that the water thickness deviations in Madagascar follow those of equatorial east Africa in the La Niña/El Niño episodes. This is, however, not the case in the past episodes (Fig. 1). Ropelewski and Halpert [16,17] also suggested that the area expected to be wet in El Niño in South America extends from northern Argentine to Uruguay (Fig.1), but the area that actually became wet in the 2006-2007 El Niño is located further to the north (Figs. 4b and 7d). The areas with anomalous precipitation, as depicted in Fig. 1, are not much revised in their recent literature [18], but Mason and Goddard [19], in their Fig.5, gives the distribution of anomalous precipitation in La Niña episodes that resembles slightly more to our result.

Ropelewski and Halpert [16-18] are based on past meteorological records and hence do not provide accurate information in areas insufficiently covered by them. GRACE will help us recognize precipitation anomalies related to ENSO all over the land area taking advantage of its global data coverage with uniform quality. As seen in Fig. 2, another La Niña episode appears to have started in 2007 spring. It would be interesting to see if similar gravity signatures to the 2005-2006 episode repeat in this new episode. Once typical spatial pattern of gravity deviation related to ENSO is clarified, an approach using averaging kernels designed to extract signal with a certain prescribed pattern [25] would offer a way to analyze time series with the highest signal-to-noise ratio.

In the present study, we demonstrated the consistency between the time-variable gravity data from GRACE and precipitation data from CMAP in regions where anomalous precipitation are expected in ENSO episodes. This is rather surprising considering that they measure essentially different 
quantities, i.e. the GRACE results reflect fluxes such as precipitation, runoff, and evapotranspiration, integrated over a certain period while CMAP gives just one of them in a non-integrated manner (there we also considered evapotranspiration, but it did not play a major role as described below).

Syed et al. [13] showed that the seasonal change in terrestrial water storage in tropical area is substantially controlled by precipitation. The consistency between water thickness deviations inferred from GRACE and CMAP in Africa and South America suggests that inter-annual changes in water thickness are also largely controlled by precipitation there. This is mainly because evapotranspiration, a flux of water from soil to atmosphere, does not vary so much from season to season in the low-latitude zone. In fact, we confirmed that the high correlation between CMAP and GRACE (Fig.8) is little affected by not calculating evapotranspiration in integrating the precipitation to simulate the soil moisture in Fig.6. This is in contrast with mid- and high-latitude regions where seasonal water storage changes are governed by changes in evapotranspiration and snow melt runoff, respectively [13]. Hence, gravity signatures of ENSO-related precipitation anomalies there could be fairly different from those in low-latitude regions.

Here we conclude as follows;

(1) Gravity deviations in El Niño and La Niña episodes recovered by GRACE were negatively correlated in Africa and South America.

(2) Water thickness anomalies inferred from CMAP monthly precipitation data were mostly consistent with those from GRACE.

(3) These anomalies match, to some extent, with empirically identified precipitation anomalies in typical El Niño and La Niña episodes in land area.

(4) Inter-annual changes in terrestrial water storage in low-latitude regions are governed mainly by precipitation.

\section{Acknowledgements}

We thank three anonymous reviewers for constructive comments to the earlier version of this article, and Ryoko Ogawa, Kazuhisa Chikita, and Shoshiro Minobe (Hokkaido University) for discussions.

\section{References}

[1] J. Wahr, M. Molenaar, F. Bryan, Time variability of the Earth’s gravity field: Hydrological and oceanic effects and their possible detection using GRACE, J. Geophys. Res.,103 (1998) 30,205-30,229.

[2] J. Wahr, S. Swenson, V. Zlotnicki, I. Velicogna, Time-variable gravity from GRACE: First results, Geophys. Res. Lett., 31 (2004) L11501, doi:10.1029/2004GL019779.

[3] B.D. Tapley, S. Bettadpur, J.C. Ries, P.F. Thompson, M.M. Watkins, GRACE measurements of mass variability in the Earth system, Science, 305 (2004) 503-505.

[4] M.E.Tamisiea, E.W. Leuliette, J.L. Davis, J.X. Mitrovica, Constraining hydrological and cryospheric mass flux in southeastern Alaska using space-based gravity measurements, Geophys. Res. Lett., 32 (2005) L20501, doi:10.1029/2005GL023961.

[5] S. B. Luthcke, H.J. Zwally, W.Abdalati, D.D. Rowlands, R.D. Ray, R.S. Nerem, F. G. Lemoine, J.J. McCarthy, D.S. Chinn, Recent Greenland ice mass loss by drainage system from satellite gravity observations, Science, 314 (2006) 1286-1289.

[6] I. Velicogna, J. Wahr, Acceleration of Greenland ice mass loss in spring 2004, Nature, 443 (2006) doi:10.1038/nature05168.

[7] D.P. Chambers, J. Wahr, and R.S. Nerem, Preliminary observations of global ocean mass variations 
with GRACE, Geophys. Res. Lett.,.31 (2004) L13310, doi:10.1029/2004GL020461.

[8] L. Fenoglio-Marc, J. Kusche, M. Becker, Mass variation in the Mediterranean Sea from GRACE and its validation by altimetry, steric and hydrologic fields, Geophys. Res. Lett., 33 (2006) L19606, doi:10.1029/2006GL026851.

[9] R. Ogawa, K. Heki, Slow postseismic recovery of geoid depression formed by the 2004 Sumatra-Andaman Earthquake by mantle water diffusion, Geophys. Res. Lett., 34 (2007) L06313, doi:10.1029/2007GL029340.

[10] K.-W. Seo, C.R. Wilson, J.S. Famiglietti, J.L.Chen, M. Rodell, Terrestrial water mass load changes from Gravity Recovery and Climate Experiment (GRACE), Water Resour. Res., 42 (2006), W05417, doi:10.1029/2005WR004255.

[11] J.W. Crowley, J. X. Mitrovica, R. C. Bailey, M. E. Tamisiea, J. L. Davis, Land water storage within the Congo Basin inferred from GRACE satellite gravity data, Geophys.Res. Lett., 33 (2006) L19402, doi:10.1029/2006GL027070.

[12] G. Ramillien, F. Frappart, A.Cazenave, A. Guntner, Time variations of land water storage from an inversion of 2 years of GRACE geoids, Earth Planet. Sci. Lett., 235 (2005), 283-301.

[13] T.H. Syed, J.S. Famiglietti, M.Rodell, J. Chen, C.R. Wilson, Analysis of terrestrial water storage changes from GRACE and GLDAS, Water Resour. Res., 44 (2008) W02433, doi:10.1029/2006WR005779.

[14] J.S. Famiglietti, Remote sensing of terrestrial water storage, soil moisture and surface waters, in The state of the planet: Frontiers and challenges in geophysics, Geophys. Monogr. Sr., vol.150 (2004), edited by R.S.J. Sparks and C.J. Hawkesworth, pp.197-207, AGU, Washington D.C.

[15] T. Oki, D. Entekhbi, T.I.Harrold, The global water cycle, in The state of the planet: Frontiers and challenges in geophysics, Geophys. Monogr. Sr., vol.150 (2004), edited by R.S.J. Sparks and C.J. Hawkesworth, pp.225-257, AGU, Washington D.C.

[16] C.F. Ropelewski, M. S. Halpert, Global and regional scale precipitation patterns associated with the El Niño/southern oscillation, Monthly Weather Rev., 115 (1987) 1606-1626.

[17] C.F. Ropelewski, M. S. Halpert, Precipitation patterns associated with the high index phase of southern oscillation, J. Climate, 2 (1989) 268-284.

[18] C.F. Ropelewski, M.S. Halpert, Quantifying Southern Oscillation-precipitation relationships, J. Climate, 9 (1996) 1043-1059.

[19] S.J. Mason, L. Goddard, Probabilistic precipitation anomalies associated with ENSO, Bull. Amer. Meteor. Soc., 82 (2001) 619-638.

[20] M. Cheng, B.D. Tapley, Variations in the Earth's oblateness during the past 28 years, J. Geophys. Res., 109 (2004) B09402, doi:10.1029/2004JB003028.

[21] S.C. Swenson, J. Wahr, Post-processing removal of correlated errors in GRACE data, Geophys. Res. Lett., 33 (2006) L08402, doi:10.1029/2005GL025285.

[22] S.L. Dingman, Physical Hydrology Second Edition, Prentice Hall, New Jersey, 2002, 646 pp.

[23] R.W. Hamon, Computation of direct runoff amounts from storm rainfall, Int. Assoc. Sci. Hydrology, Publication 63, 1963.

[24] E.A.B. Eltahir, B. Loux, T.K. Yamana, A. Bomblies, A see-saw oscillation between the Amazon and Congo basins, Geophys. Res. Lett., 31 (2004) L23201, doi:10.1029/2004GL021160.

[25] S. Swenson, J. Wahr, Methods for inferring regional surface mass anomalies from Gravity Recovery and Climate Experiment (GRACE) measurements of time-variable gravity, J. Geophys. Res. 107 (2002), 2193, doi:10.1029/2001JB000576. 


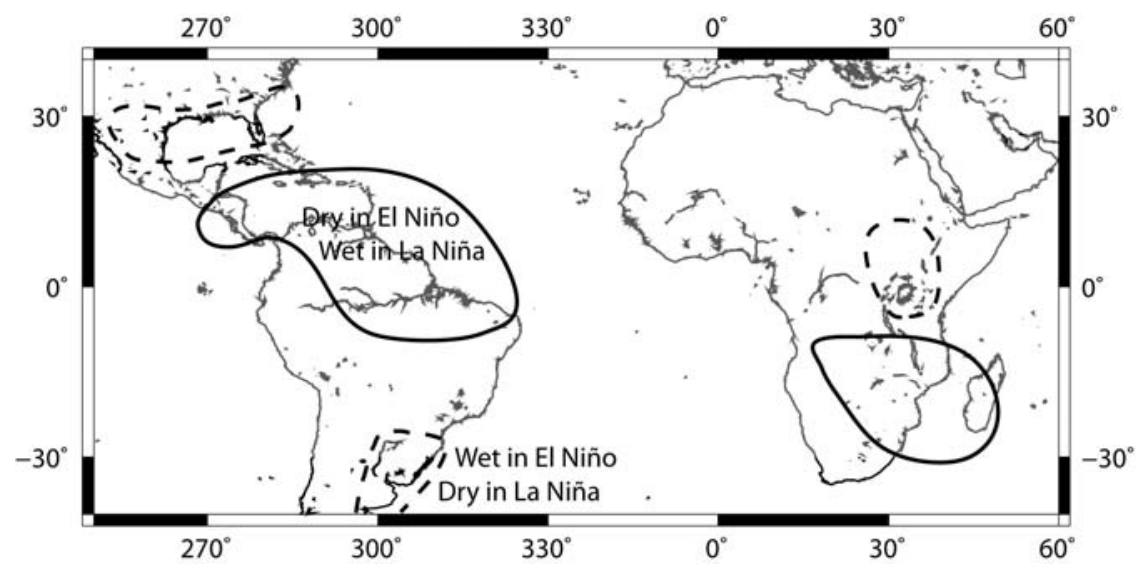

Fig.1. Past meteorological records show that precipitation anomalies occur in various parts of the world during El Niño episodes. Precipitation tends to decrease (increase) in the areas within solid (broken) curves [16], which reverse in La Niña episodes [17].

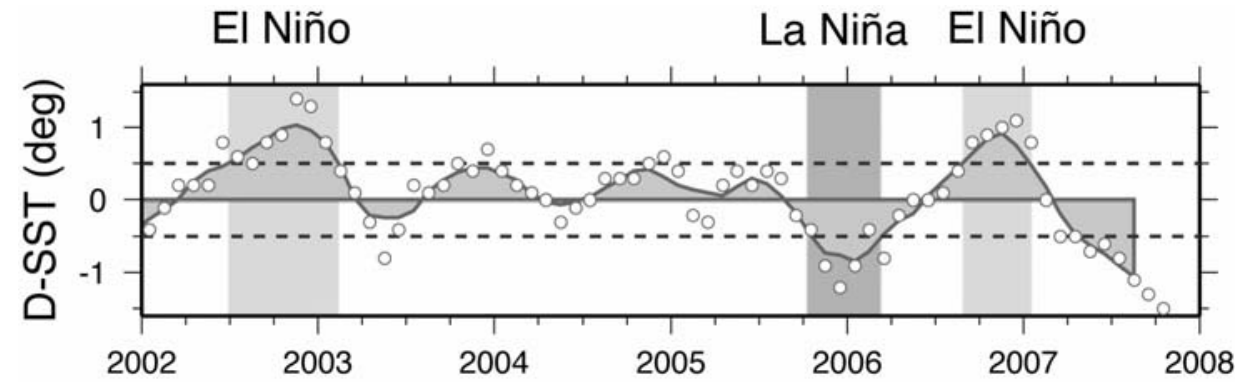

Fig.2. Monthly differences (open circles) between the SST in the El Niño monitoring area and the reference temperature, from the Japan Meteorological Agency website (www.jma.go.jp). The black curve shows the 5 months moving average. In an El Niño/La Niña episode, the black curve stays above/below the \pm 0.5 degree level (dashed lines) for a half year or more.

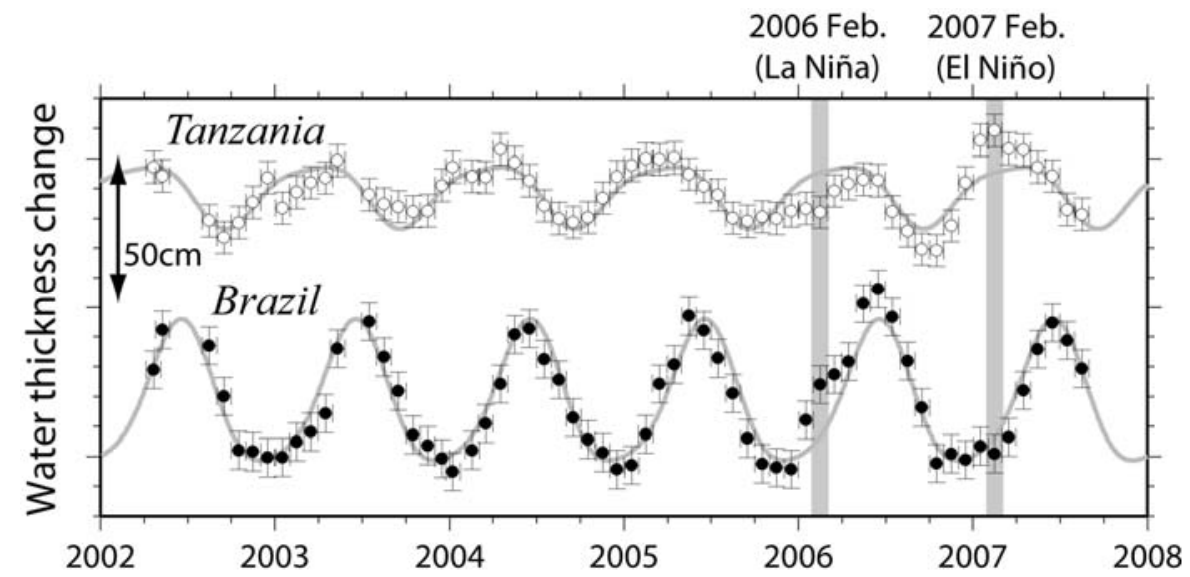

Fig. 3. Changes of gravity values expressed as variations of surface water thicknesses, from GRACE monthly data sets, at a point in Tanzania, Eastern Africa (5S 30E), and in Brazil, South America (0N 60W, see Fig.4 for the positions). Solid curves show best-fit models composed of annual and semiannual terms. Vertical error bars show standard deviation inferred a posteriori based on post-fit residuals, and horizontal error bars show duration represented by the individual data. At the two 
epochs, 2006 February and 2007 February (narrow vertical gray lines indicates the sampled epochs, and not the episodes themselves) representing El Niño and La Niña, respectively, monthly values deviate from the model curves. Geographic extent of such deviations is shown in Fig. 4.
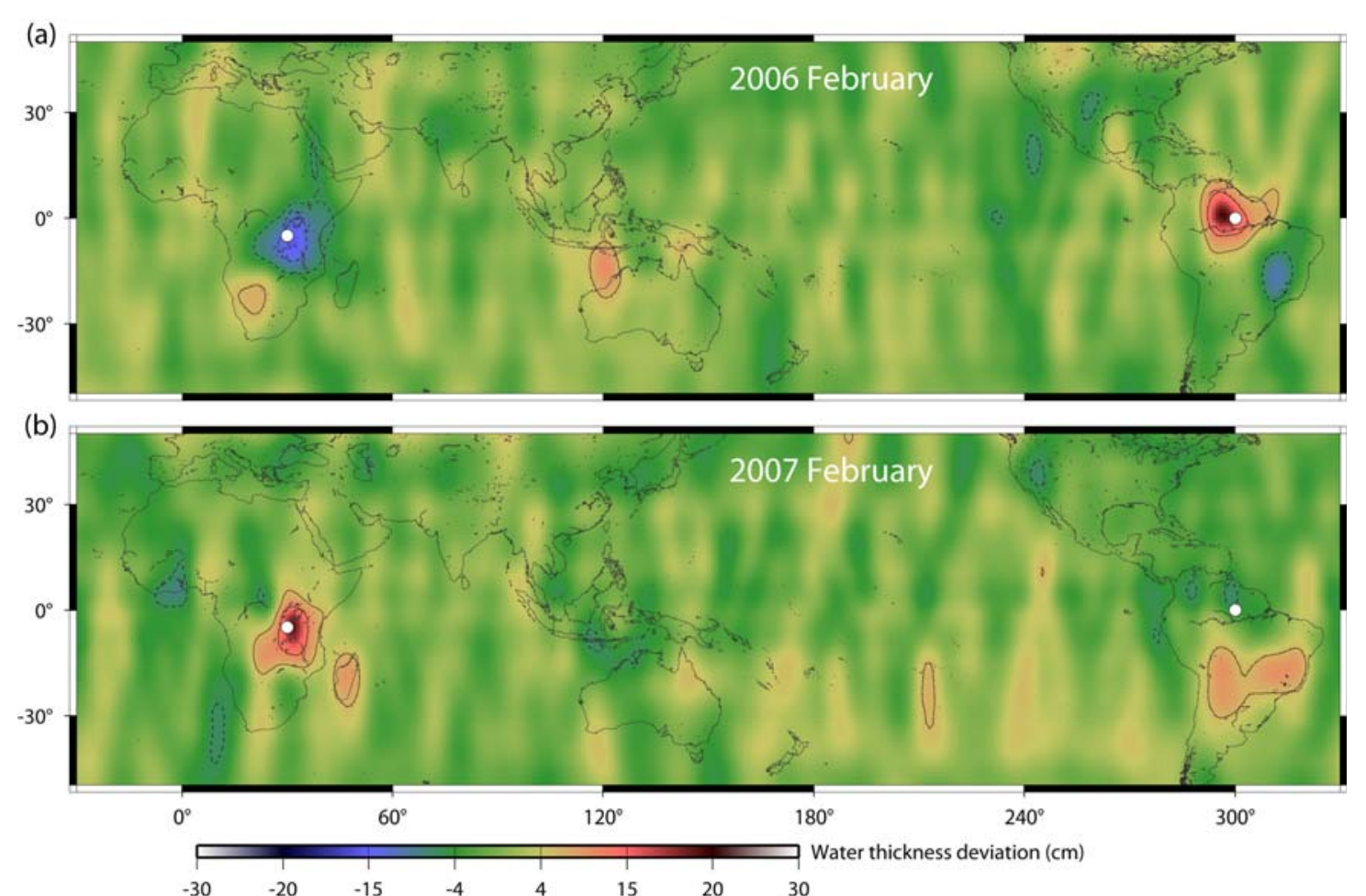

Fig. 4. Gravity deviations from standard seasonal curves converted into water thickness deviations in February 2006 (a) and February 2007 (b), which represents the recent La Niña and El Niño episodes, respectively. Contours show \pm 6 and $\pm 12 \mathrm{~cm}$ (broken contours are negative). The $\pm 6 \mathrm{~cm}$ contours approximately correspond to the $2 \sigma$ error inferred by the time series analysis (Fig.3). The two white circles show points in Tanzania and Brazil, whose time series are plotted in Fig. 3. A Gaussian filter with the averaging radius of $500 \mathrm{~km}$ has been applied. Stripes striking north-south are apparent signals coming from correlated errors [21].
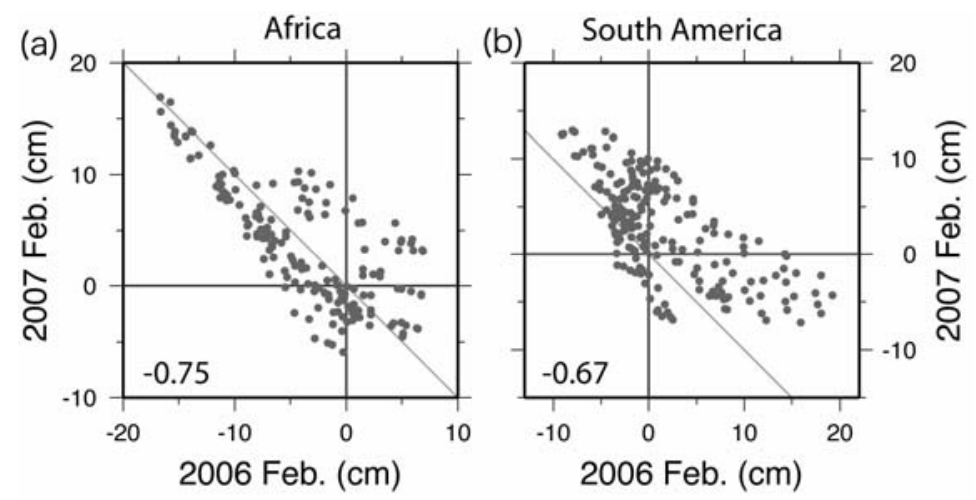

Fig.5 Correlation between water thickness deviations in 2006 and 2007 February at $2.5 \times 2.5$ degree grid points in the African (a) (latitude 30S-5N, longitude 10E-55E) and South American (b) (latitude 35S-10N, longitude 285E-325E) continents. Numbers in the figure indicates the correlation coefficients. 


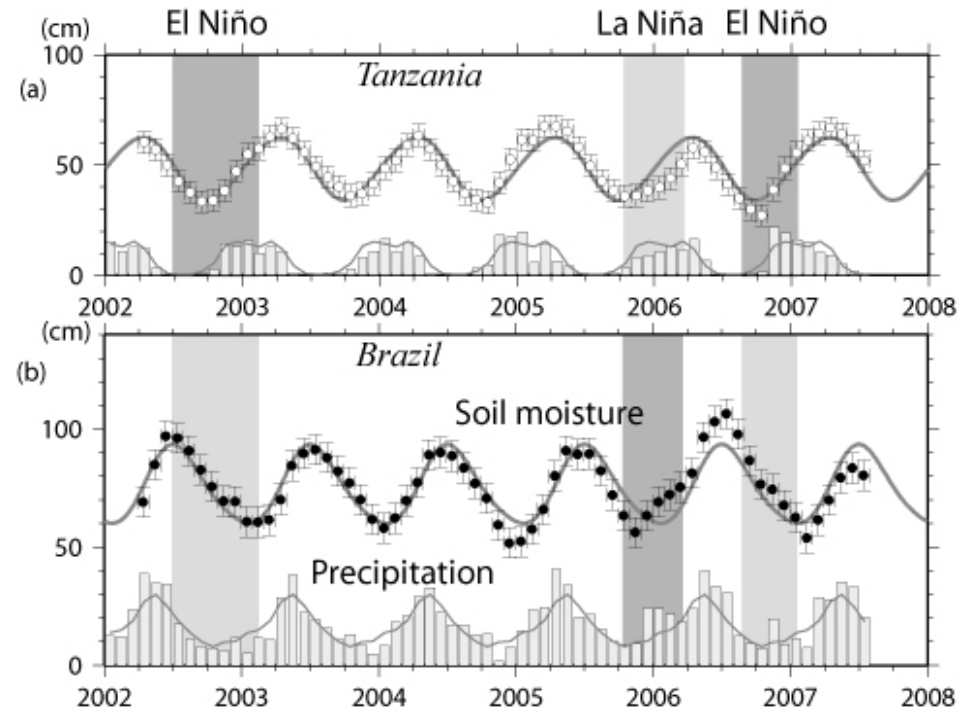

Fig. 6. Time series of soil moisture anomalies in Tanzania, Africa (a) and Brazil, South America (b), inferred by integrating CMAP monthly precipitation data. Only the seasonal components are shown (their offsets are arbitrary). The best-fit seasonal curve and error bars are obtained in the same way as Fig. 3. The CMAP data are shown by vertical bars at the bottom (the curve indicates the average since 1979). In typical episodes, precipitations tend to be larger/smaller during the periods shown in medium/light gray [16, 17], which is clear in the 2005-2006 and 2006-2007 episodes but not in the 2002-2003 episode.
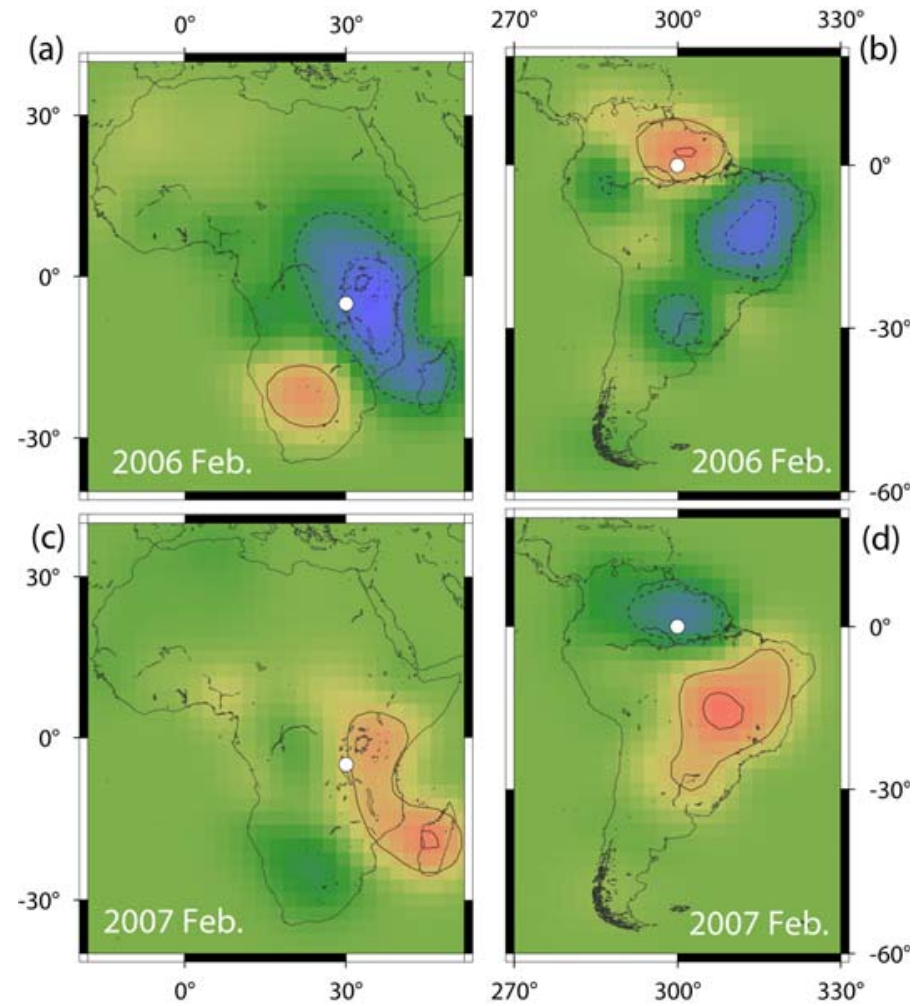

Fig. 7. Soil moisture anomalies in terms of water thickness anomalies in February 2006 (a,b) and 2007 $(c, d)$, in Africa $(a, c)$ and South America (b,d), inferred by integrating the CMAP monthly precipitation data. The same Gaussian spatial filter as in Fig. 4 has been applied. The contours and color schemes are same as Fig. 4. 

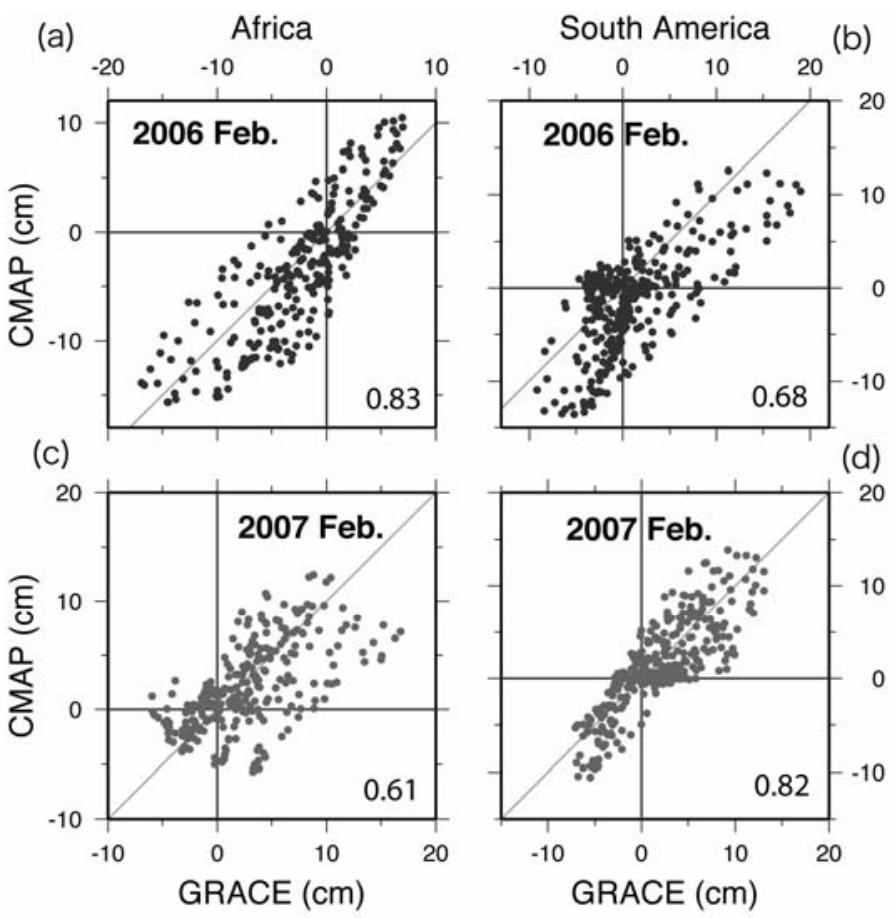

Fig.8 Correlation between water thickness deviations by GRACE and CMAP in 2006 (a,b) and 2007 (c,d) February at $2.5 \times 2.5$ degree grid points in the African (a,c) (latitude 30S-5N, longitude 10E-55E) and South American (b,d) ) (latitude 35S-10N, longitude 285E-325E) continents. Numbers in the figure indicates the correlation coefficients. 